\title{
DIVISÕES DE CLASSE E POBREZA RELATIVA NO BRASIL
}

\section{CLASS DIVISIONS AND RELATIVE POVERTY IN BRAZIL}

\author{
José Alcides Figueiredo Santos*
}

\section{Introdução}

As mudanças recentes da distribuição de renda no país têm alterado as desvantagens de recompensas das pessoas situadas na base da estrutura social. Este estudo explora as possibilidades que um enfoque de classe social, centrado na ideia de controle de recursos valiosos, pode oferecer para o entendimento dos processos de privação relativa na ampla e heterogênea base da estrutura social brasileira. Levando em conta a importância do desenvolvimento e da elaboração teórica no tratamento da realidade empírica, são consideradas as reflexões e os enfoques da questão da pobreza que valorizam, de algum modo, os planos das relações sociais, da estruturação das oportunidades e das capacidades dos atores. São incorporadas ao debate teórico, igualmente, abordagens sociológicas ou econômicas da pobreza que destacam o papel do controle de ativos. Revisa-se a maneira como a noção de classe social tem sido utilizada para a abordagem deste problema na sociologia contemporânea. Realiza-se com esta finalidade uma caracterização dos agrupamentos de trabalhadores típicos e das posições de classe destituídas no Brasil (SANTOS, 2005, 2010 e 2014).

São avaliadas as mudanças nas chances relativas (odds ratio) dos integrantes das categorias de estar numa situação de pobreza de renda e de pobreza de recursos. A evolução dos riscos absolutos e relativos de ser pobre envolve uma articulação entre desvantagens dadas, meios mobilizáveis e fatores protetivos desigualmente distribuídos entre as categorias. A estrutura da desigualdade existente pode fazer com que os progressos realizados, ou as situações negativas encontradas, não se distribuam de modo a

\footnotetext{
* Doutor em sociologia e professor da Universidade Federal de Juiz de Fora (UFJF /Juiz de Fora/MG/BR). As investigações que realiza sobre classe social, raça, gênero, renda e saúde no Brasil têm sido publicadas nos principais periódicos de Ciências Sociais do país. josealcidesf@yahoo.com.br.
} 
favorecer mais ou desfavorecer menos os grupos em maior desvantagem. A noção de chances relativas oferece o benefício de captar, numa perspectiva comparativa entre os grupos, a realidade resultante da razão entre as oportunidades negativas de ser pobre (fatores incrementadores de risco) e as oportunidades positivas de não ser pobre (fatores minimizadores e protetivos).

Num contraponto à noção de pobreza como um padrão fixo de necessidades básicas, o conceito de pobreza relativa norteia o estudo por incorporar e revelar a dimensão de comparação entre os grupos e as interdependências - entre os padrões para viver e os meios para desenvolver atividades na sociedade. Agrega-se à análise da pobreza relativa de renda a dimensão de acúmulo de recursos, visando incorporar na representação da privação relativa influências diferenciadas dos fluxos de renda e suas flutuações. A abordagem da pobreza na perspectiva de classe social leva em conta que este fenômeno envolve processos mais extensivos, associados aos mecanismos institucionalizados de distribuição dos recursos valiosos, cujas consequências não se circunscrevem a um grupo estritamente diferenciado da maioria. Os processos subjacentes à pobreza impactam em diversos grupos e repercutem em várias direções; ao mesmo tempo, são socialmente seletivos na estruturação dos riscos de pobreza e afetam com mais força os membros mais vulneráveis das classes mais expostas ou menos protegidas dos fatores de empobrecimento (LAYTE; WHELAN, 2002; GOLDTHORPE, 2010). Essas orientações representam uma contribuição sociológica relevante para o entendimento das desvantagens e dos riscos de pobreza que estão conectados às dimensões institucionais e relacionais da estrutura social.

\section{Pobreza relativa, exclusão social e con- trole de ativos}

Embora a noção de pobreza seja um tanto intuitiva, existe muito debate sobre o conceito e sua forma de mensuração. Pobreza diz respeito a um estado de falta de recursos que leva a um padrão de vida insuficiente ou baixo. 0 nível insuficiente pode ser considerado em termos de um mínimo de necessidades humanas de sobrevivência ou de padrões relativos de bem-estar em uma sociedade. A adoção de uma linha de pobreza absoluta baseia-se numa quantidade mínima de recursos que cada pessoa possui, sem relação com as situações e experiências das demais pessoas, como se os padrões de vida não estivessem inter-relacionados. A dicotomia absoluto/relativo, no entanto, tende a se mostrar problemática quando entra em questão a mensuração do conceito, pois não há como fugir do julgamento das necessidades e da influência do contexto em que se vive (PLATT, 2006). A noção e a mensuração da pobreza absoluta como um padrão pré-determinado de "necessidades básicas” têm sido aplicadas particularmente em países periféricos ou em desenvolvimento, mas existe certo ceticismo a respeito da capacidade de um limiar fixo de bem-estar capturar a complexidade da pobreza. Nos países desenvolvidos, têm sido preferidas medidas relativas de pobreza que captam as diferenças de condições de vida entre o pobre e a maioria da sociedade, em um contexto nacional e histórico concreto. Medidas relativas são inseridas em um ambiente social, refletem os padrões prevalentes de necessidades, e mostram-se mais pertinentes para a investigação sociológica das causas e tendências da pobreza (BRADY, 2003). Na literatura econômica, continua a circular a rejeição da noção de pobreza relativa sob o ar- 
gumento de que é sinônimo de desigualdade, como se a pobreza devesse obrigatoriamente se ancorar em algum tipo de absoluto (SOARES, 2009). Entretanto, enquanto a desigualdade envolve essencialmente a comparação entre grupos, a pobreza relativa acrescenta a esta comparação a noção de incapacidade de realizar certas necessidades, relacionadas à participação na sociedade, cujas definições e satisfações dependem dos contextos sociais (LISTER, 2004). Na avaliação da pobreza, não faz sentido ignorar o que ocorre em torno dos pobres, pois os bens funcionam como meios necessários para desenvolver atividades na sociedade em que se vive (ATKINSON, 1998). A adoção de uma linha móvel de pobreza, referida a um ponto intermediário da distribuição, como a renda mediana, faz com que o limiar da pobreza fique em sintonia com as mudanças nos níveis típicos da renda, na distribuição da renda entre a população e nos condicionamentos das necessidades. A noção de pobreza se aproxima da ideia de divisão social ao ser realçada a dimensão relativa, comparativa e de exclusão social. A visão sociológica da pobreza como divisão social implica em compreender os fatores que estruturam as chances de vida das pessoas e geram diferenças marcantes nos riscos de pobreza (PLATT, 2006).

Insatisfações com a estreiteza teórica dos conceitos e medidas de pobreza levaram ao desenvolvimento da noção de exclusão social. Embora o conceito ainda careça de uma fundamentação mais clara, pode sugerir novas questões e facilitar inovações metodológicas. A noção de capacidade pode prover esta base e servir de elo com o problema da pobreza. Esta aproximação se faz com a consideração de padrões relativos e relacionais que estão enraizados no contexto social. Os recursos econômicos mantêm-se como os principais precursores da exclusão social, mas o conceito reflete dimensões sociais e culturais mais amplas. Exclusão social concebida em termos de capacidades tem um sentido absoluto, ao significar ausência de níveis básicos de funcionamento social, mas reflete uma dimensão relativa quando são consideradas as insufıciências de meios econômicos (BRADY, 20035). Amartya Sen (2000) situa a noção de exclusão social dentro da visão mais geral de pobreza como um resultado da privação de capacidades. A exclusão social, nesta ótica, é entendida como uma parte constitutiva da privação de capacidade, assim como uma causa instrumental de diversas falências de capacidade. A linguagem da exclusão tem o mérito de focalizar a atenção nas características relacionais da privação. Entretanto, a natureza dos processos causais é crucial para invocar, ou não, a ideia de exclusão. Ela pode oferecer um entendimento melhor dos diversos fenômenos de privação e pobreza que envolvem a operação de obstáculos relacionais. Os processos de falência de capacidade e pobreza, de outro lado, em muitas situações nascem da existência de termos desfavoráveis de inclusão e de participação adversa. A natureza causal do problema - se exclusão social ou inclusão desfavorável -, deve ser claramente diferenciada. Entretanto, vista nesse ângulo mais abrangente da privação de capacidades, não existe dificuldade em situar e articular as diversas origens e formas de manifestação da falência de ter capacidades básicas adequadas (SEN, 2000). Argumenta-se na literatura econômica que o conceito de exclusão social, mais amplo do que a noção de pobreza, reflete a natureza multidimensional da desvantagem, o caráter dinâmico dos processos excludentes, assim como as implicações da inade- 
quação de participação social e da falta de poder (NOLAN; MARX, 2011).

Charles Tilly (2007) contesta a visão da desigualdade e da pobreza como resultantes da competição entre indivíduos num contexto em que as regras do jogo são mutuamente aceitas: enfatiza o papel dos processos sociais de exclusão na geração da desigualdade e o impacto da desigualdade na pobreza entre populações excluídas; e considera que as distinções e interações organizadas entre membros de diferentes categorias geram mais vantagens para um desses conjuntos de pessoas do que para o outro. Essa abordagem está centrada na exclusão de membros das categorias subordinadas dos benefícios gerados pelo controle de recursos. A exclusão produz e mantém a pobreza relativa do excluído. 0 impacto da exclusão na experiência de pobreza absoluta do excluído depende dos fatores: 1) a extensão da exclusão; 2) a disponibilidade de recursos alternativos; 3) o montante absoluto da parte que fica com as categorias subordinadas. A exclusão produz pobreza, mais diretamente, na medida em que os recursos cruciais que são controlados comprometem os meios de vida da maioria das pessoas na população. Os canais organizados categoricamente, em vez da ação puramente individual, facilitam a superação da pobreza numa escala maior. A redução da exclusão estimula o escape individual e coletivo da pobreza. Essa redução pode se dar pela segmentação ou multiplicação de recursos produtores de valor, a ação coletiva dos excluídos, a descoberta ou criação de novos recursos por estas categorias e a subversão das fronteiras entre estas categorias (TILLY, 2006).

Estudos de estratificação têm enfatizado, a partir dos anos 90, o papel do controle de ativos ou riqueza, como algo distinto da renda, no condicionamento das oportunidades econômicas ou chances de vida. A literatura tem demonstrado a influência da origem social na capacidade de acumular ativos no curso da vida e as marcantes diferenças na acumulação de ativos entre diferentes segmentos da população, mas tem olhado pouco para as consequências da desigualdade de ativos (MORILLAS, 2007). As contribuições sociológicas nesse campo muitas vezes têm se mantido programáticas, focadas nas estratégias de escape da pobreza. Propõem-se estratégias de construção de ativos que teriam o potencial de alterar os padrões sociais em que a pobreza é gerada e reproduzida. A redução da pobreza envolve o desenvolvimento de atividades que podem auxiliar a aquisição individual ou coletiva da propriedade de ativos, a capacidade de efetivamente manejar esses ativos e de sustentar ou melhorar a qualidade desses ativos. Os ativos financeiros, humanos, sociais e culturais podem propiciar o desenvolvimento de capacidades e favorecer o aproveitamento de oportunidades (OLIVER; GRANT, 2000). Morillas esboçou uma narrativa explicativa dos elos ao nível micro dos efeitos da riqueza como um dispositivo que condiciona as oportunidades e realizações socioeconômicas. As (des)vantagens acumuladas e sedimentadas no curso do tempo, entre as gerações e na trajetória da geração atual, produzem a desigualdade de riqueza, e esta, por sua vez, cria uma rede de segurança para os seus possuidores que serve de proteção contra as dificuldades, e de estímulo às iniciativas de risco das quais podem ser obtidas vantagens. 0 controle de um nível mínimo de recursos, ao garantir suficiente bem-estar e segurança, assim como certo isolamento dos constrangimentos do mercado, favorece e incentiva o aproveitamento das oportunidades de mobilidade e progressão socioeco- 
nômicas. As proposições testadas empiricamente confirmaram a expectativa teórica de que os ativos estão associados com as oportunidades de aquisição de rendimentos (MORILLAS, 2007). Estudos econômicos inspiraram-se no trabalho de Shapiro e Oliver (1995) para elaborar a noção de "pobreza de ativos”. Famílias que não possuem um colchão de rede de segurança (safety-net cushion), formado pela posse de ativos, são consideradas em posição econômica vulnerável. Haven e Wolff (2004) consideram que a pobreza de ativos compreenderia aquelas famílias nos Estados Unidos com ativos insuficientes para atender às suas necessidades básicas, por um período de três meses, na hipótese de perda da renda. Estipulam duas definições de ativos: mais ampla de valor líquido, ou seja, o valor de todos os ativos vendáveis, menos os débitos; mais restrita de ativos líquidos, isto é, os ativos financeiros ou em dinheiro que possam ser prontamente convertidos em moeda. A família seria pobre em ativos se o valor do que possui for inferior a $25 \%$ da linha de pobreza para famílias do seu tamanho e composição. A medida pode ser combinada com medida mais tradicional de pobreza de renda, de modo a considerar a pobreza nas duas dimensões (HAVEMAN; WOLFF, 2004). A crítica ao paradigma da pobreza de renda oferece como estratégia alternativa uma mudança de foco explicativo para as dotações. A distribuição particularmente de ativos de diferentes tipos, cujos processos estão além do controle dos indivíduos, determinaria a ocorrência da pobreza. A pobreza é definida em termos de um conjunto multidimencional de dotações e acesso a mercados e bens. A equalização de dotações ou oportunidades demanda a redistribuição de ativos. Entretanto, dados os impedimentos ou dificuldades em fazer a transferência direta e imedia- ta dos próprios ativos, a redistribuição pode envolver a renda dos ricos que seria canalizada para viabilizar um processo de acumulação de ativos entre os pobres (BOURGUIGNON, 2006).

\section{Modelos de classe social da chance de pobreza}

Grusky e Weeden (2008) consideram que os instrumentos de mensuração existentes não são plenamente adequados para representar a estrutura da pobreza, já que sua representação envolve considerar e esclarecer a configuração e o formato que ela assume. Além disso, índices estatísticos de natureza meramente sumária não capturam a estrutura de grupos institucionalizados. 0 espaço da pobreza tem descontinuidades compostas por agrupamentos distintos de condições, e as categorias constituídas não podem ser traduzidas em nenhuma graduação unidimensional. David Gruksy (2006) caracteriza a prevalência no tratamento sociológico da questão da desigualdade e da pobreza de dois conjuntos de modelos de classe social. 0 primeiro conjunto expressa uma razão ou motivação estruturalista; neste âmbito a maioria das formulações compartilha a suposição de que as classes são agrupamentos pré-existentes de condições estruturais que compõem uma realidade diferenciada. A visão Weberiana clássica enfatiza o papel de um conjunto de dotações na estruturação de chances ou oportunidades de vida típicas. 0 segundo campo de interpretação expressa uma razão culturalista: as classes envolveriam a existência de agrupamentos socialmente fechados caracterizados por culturas distintas que influenciariam as atitudes, comportamentos e mesmo as preferências dos seus membros. Na literatura, as relações entre as condições mais objetivas e esse 
complexo cultural têm sido entendidas de três modos. As culturas de classe são meios culturalmente prescritos, na forma de regras práticas, que expressam respostas comportamentais às condições institucionais prevalentes. Em outra visão, corresponde a fins culturalmente prescritos que envolvem a própria avaliação dos objetivos perseguidos pelos atores, o que pode gerar "culturas de oposição" aos valores mais influentes de outras classes. As culturas de classe dos pobres têm sido consideradas também como mal adaptadas, pois filtram informação e geram um comportamento de baixa eficácia para lidar com as circunstâncias desfavoráveis (GRUSKY; KANBUR, 2006). Wilson (2006) entende que o ambiente em que vivem os grupos incorporam constrangimentos e oportunidades de natureza tanto estrutural quanto cultural. Os padrões de comportamento da subclasse representam adaptações culturais ao bloqueio sistemático de oportunidades no ambiente da cidade e da sociedade como um todo. Esse processo se reflete nos hábitos, qualificações, estilos e atitudes a que a pessoas estão expostas, que passam a constituir os traços e características dos grupos, e ajudam a explicar os resultados sociais divergentes entre os grupos.

0 estudo da pobreza deve englobar uma perspectiva relacional e ir além da quantificação de alterações nos seus padrões de incidência, intensidade e severidade ao nível agregado. Uma elaboração do nexo entre classe social e pobreza emerge de um entendimento mais abrangente da dinâmica de riscos e proteções que afetam as trajetórias de indivíduos e grupos em relação aos limiares de pobreza. Duas questões preliminares são consideradas e articuladas na interpretação sociológica que orienta o presente estudo do fenômeno. Determinações sociais presidem a distribuição não aleató- ria da pobreza na sociedade e esta não pode ser adequadamente representada como uma minoria homogeneamente diferente e desconectada da maioria. A pobreza origina-se de relações sociais institucionalizadas por meio das quais uma distribuição altamente desigual dos recursos econômicos é criada e mantida. Vincula-se à classe social já que diz respeito à existência de diferenças socialmente estruturadas no risco de ser pobre. A pobreza envolve processos mais "extensivos", que se espraiam em várias direções na sociedade, afetando particularmente os membros mais vulneráveis dos estratos em maior desvantagem (T0WNSEND, 1979; NOLAN; WHELAN, 1999; LAYTE; WHELAN, 2002; GOLDTHORPE, 2010). Em virtude das posições de classe que ocupam, os indivíduos possuem diferentes recursos que condicionam as possibilidades e os constrangimentos na obtenção de segurança, estabilidade e perspectiva econômicas (GOLDTHORPE; MCKNIGHT, 2006). 0 conceito e a mensuração de classe social têm sido considerados nos estudos de pobreza e privação na Europa, com resultados relevantes e promissores. Estas iniciativas têm sido favorecidas pelo próprio processo de compatibilização e integração dessa noção sociológica e suas estratégias de mensuração nas estatísticas sociais da União Europeia. Estudo envolvendo quatorze países europeus mostrou que a força do efeito de classe social aumenta na medida em que o foco explicativo se move da pobreza de renda para a privação e desta para a pobreza consistente (renda mais privação). 0 efeito de classe social aumenta igualmente quando se introduz a dimensão temporal para captar tanto a pobreza persistente de renda quanto a privação persistente (WATSON; WHELAN; MAITRE, 2010). Estudo comparativo europeu constata uma 
clara hierarquia de classe nos riscos relativos deter persistente vulnerabilidade econômica nos nove países estudados. A classe profissional e gerencial ocupa a posição mais favorável seguida das ocupações intermediárias. Os autoempregados e supervisores e técnicos vem depois na hierarquia de classe. Já as ocupações de serviços e técnicas de menor grau estão próximas ao grupo não manual de rotina. Em todos os casos, mas com variações de grau entre países, as classes de ocupações de rotina estão em maior desvantagem. A investigação revela padrões de diferenciação por classe social dentro dos regimes de bem-estar social na Europa. Os níveis absolutos de vulnerabilidade são comparativamente elevados entre as classes sociais baixas nos regimes de bem-estar menos afluentes, enquanto as discrepâncias relativas de classe são mais marcantes em um número de regimes de bem-estar mais afluentes (NOLAN; WHELAN, 2011).

Neste período mais recente de queda da desigualdade de renda no Brasil, ainda são poucos os estudos que fazem alguma relação entre classe social e pobreza usando dados empíricos de alcance nacional. Um artigo utilizou linhas regionalizadas de pobreza absoluta no ano de 2004 para demonstrar que a proporção de pobres no Brasil varia claramente conforme as posições sociais ocupadas pelas pessoas. 0 controle de capital, qualificação e o exercício de autoridade diminuem significativamente as possibilidades de ser pobre. A incidência da pobreza absoluta é de apenas 2\% nos empregos de classe média, porém alcança 36\% no trabalhador elementar não agrícola, 33,4\% no trabalhador elementar agrícola, 35,1\% no empregado doméstico e $27 \%$ no trabalhador não elementar, mas informal (FURTADO, 2011). Um estudo das mudanças do perfil da pobreza absoluta, no período de 2004 a 2009 no Brasil, ao olhar para o tipo de emprego do pobre, ofereceu indicações acerca da natureza "extensiva" dos processos que levam à pobreza, pois condições diversas como produtor agrícola, empreendedor (autônomo), empregado informal e empregado formal, estão "bem" representadas entre os pobres e os vulneráveis. Entretanto, a pobreza e a vulnerabilidade estão menos associadas à condição de empregado formal. Já a redução da proporção de empregos formais entre os pobres no período, mostrou que a ocupação desse tipo de emprego passou a restringir ainda mais a possibilidade de ser pobre (OSÓRIO et al., 2011).

\section{Categorias de classe focalizadas e méto- dos de análise}

\section{1. Características de classe da base da estrutura social}

A noção de classe social que orienta a investigação baseia-se na ligação entre as classes, o controle de ativos e a desigualdade. Classes podem ser definidas estritamente em termos de relações de propriedade e as desigualdades entre elas podem ser deduzidas da assimetria previamente estabelecida na distribuição dos ativos. Divisões de classe são constituídas por desigualdades de poderes e direitos sobre ativos geradores de valor que produzem vantagens e desvantagens entre categorias. Ativos geradores de valor são recursos cujo controle e emprego aumentam o valor transferível de bens e serviços. As relações de propriedade e poder na sociedade capitalista geram formas de desigualdade estruturada e apoiada pelo controle assimétrico sobre os recursos econômicos, o trabalho e a renda (TILLY, 1998; WRIGHT, 2005; ROEMER, 1988). Essa, noção permite 
construir uma solução unificadora capaz de caracterizar o conjunto da estrutura social do Brasil e, como parte da base da sua hierarquia social, as circunstâncias de classe social que este estudo focaliza: 1) a classe trabalhadora típica; 2) os processos de destituição e suas diferenciações. 0 trabalhador típico representa a categoria majoritária e de grande densidade social. Caracteriza-se por possuir o controle pessoal do ativo de capacidade de trabalho, mas é constrangido a ceder ao empregador parte dos frutos do emprego produtivo desta capacidade. Este contingente mantém uma posição claramente subordinada na organização social do trabalho em relação à propriedade de capital, ao controle de credenciais e ao exercício de autoridade. As relações de emprego em que se encontra inserido preservam de modo mais típico as interdependências assimétricas características dos processos de dominação e exploração. Foram apresentados adicionalmente dados relativos ao autônomo agrícola: a categoria retrata a situação diferenciada da pequena produção agrícola, onde existe o controle da terra como ativo produtivo, porém sem a contratação de trabalho assalariado. As demais categorias da tipologia de classes foram omitidas visando preservar o foco escolhido (SANTOS, 2010 e 2014).

0 modelo de classe social considerado padrão nos estudos de pobreza nos países desenvolvidos corresponde a uma formulação de três classes: uma subclasse virtualmente sem engajamento no mercado de trabalho; o trabalhador pobre com vinculo precário num trabalho ou emprego de baixo-salário; e o grupo pobre no setor informal com uma conexão precária com o autoemprego (GRUSKY; WEEDEN, 2008). Em vez de transpor esta solução para a realidade nacional, o estudo utiliza uma caracterização socioeconômica específıca do gran- de, diversificado e heterogêneo agregado destituído de ativos que compõe a base da estrutura social no Brasil. Na abordagem deste agrupamento vale-se de uma extensão teórica do princípio de exclusão de ativos ou recursos econômicos valiosos para delimitar conceitualmente este amplo agrupamento social (SANTOS, 2010 e 2014). Em um sistema em que os ativos são desigualmente distribuídos, os agentes que não têm certo montante de ativos estão "livres para perder" (ROEMER, 1988). Instalam-se processos de destituição socioeconômica quando se intensifica a exclusão, a insuficiência e a depreciação dos ativos produtores de valor. 0 trabalhador elementar é destituído por um processo de elevada depreciação do valor da sua capacidade de trabalho devido às circunstancias de forte assimetria em que o trabalho manual simples é desenvolvido. 0 trabalho assalariado de produção de valores de uso para o consumo direto de um domicilio, realizado pelo empregado doméstico, além de ser de natureza não coletiva, isolada e dispersa, em que os poderes e direitos no trabalho são muito assimétricos, sofre de uma depreciação estrutural e intrínseca associada ao fato de ser um emprego terminal (dead-end) em que existe quase nenhuma chance de progressão nesta modalidade de ocupação. 0 autônomo precário é literalmente destituído de ativos, seja de capital ou de qualificação escassa, e vê-se compelido a reproduzir a sua atividade nos interstícios do mercado de produtos e serviços. A dificuldade de acumular ativos, a grande concorrência entre iguais, a demanda insuficiente ou incerta, as inseguranças quanto à operação cotidiana da atividade, conjugam-se para depreciar o retorno associado à aplicação do esforço de trabalho na atividade. 0 agrícola precário é destituído devido ao montante insuficiente 
de ativos de terra que possui, seja em função da incerteza que cerca o seu controle, ou face às limitadas possibilidades de aplicação rentável do que possui no mercado. Esse produtor agrícola possui terra pouca ou insuficiente: na condição de posseiro, não tem o domínio legal sobre a sua posse, ou vê-se compelido a vender a totalidade ou parte (ou a maior parte) da sua produção principal para o consumidor direto em mercados meramente locais. Aproxima-se do prognóstico teórico de destituição econômica de um modo próprio à atividade agrícola (SANTOS, 2010 e 2014).

Entende-se que os mecanismos de exclusão, restrição e depreciação de ativos, nas suas várias manifestações, como ativos de capital, terra, qualificação, emprego e força de trabalho, estão associados, em maior ou menor grau, aos riscos de pobreza expressa neste estudo como um limiar móvel e relativo que reflete as mudanças de padrões de vida, as comparações entre grupos e as influências do contexto social abrangente em que pobres e não pobres estão inseridos. A distribuição de recursos valiosos envolve a operação de padrões institucionalizados e os riscos de ser pobre são socialmente estruturados, o que faz com que os processos de empobrecimento impactem mais entre os membros mais vulneráveis dos estratos sociais em maior desvantagem (GOLDTHORPE, 2010).

\subsection{Métodos de análise}

0 estudo recorre a modelos logísticos para avaliar a evolução das chances relativas das categorias da base da estrutura social de estar em situação de pobreza em comparação às posições mais privilegiadas compostas como um conjunto por capitalista, especialista autônomo, empregado es- pecialista e gerente. De modo diferenciado dos estudos econômicos tradicionais, o artigo privilegia a noção de pobreza relativa, caracterizada por estar abaixo do limiar de 70\% da mediana, no critério de padrão de vida considerado. Além disso, introduz uma abordagem de pobreza relativa de recursos, visando captar dimensões das circunstâncias econômicas que vão além dos fluxos de renda. A análise adota uma linha móvel de pobreza, referida à mediana da renda, de modo a refletir a evolução dos níveis típicos de renda, assim como as mudanças nos padrões sociais de necessidades básicas. Como a mediana da renda não é alta no Brasil, ao contrário dos países mais ricos, o uso do limiar de 70\% da mediana mostra-se razoável. Comparações feitas com os níveis de pobreza absoluta, calculados pela metodologia de Sonia Rocha (2003), mostram que não se propõe um limiar "exagerado". No ano de 1992, base de comparação, a proporção de pobreza absoluta na população era de $44 \%$, e a de pobreza relativa era de $29 \%$ entre os que têm uma posição de classe. Nos anos posteriores, os níveis de pobreza absoluta ficam muito próximos dos níveis de pobreza relativa que são considerados na análise: $34,0 \%$ contra 35,2\% de pobreza relativa em 2002 e $21,9 \%$ contra $21,7 \%$ em 2009 . Os dois indicadores, no entanto, passam a divergir bem em 2011 (20,6\% contra 30,5\% de pobreza relativa) (IETS, 2013a e 2013b). Essa discrepância surge particularmente devido à elevação da mediana do trabalho principal que passou de 673 Reais em 2009 para 800 em 2011, em valores de 2011.

Os efeitos das posições de classe foram estimados na forma de chances relativas (odds ratio) ajustadas. Todos os coeficientes nas tabelas foram expressos em termos de mudanças percentuais na razão entre as 
chances ou chances relativas das categorias confrontadas (Odds Ratio - ${ }^{*}$ 100). Os dados apresentados mostram o quanto aumentam em percentagem as chances de ser pobre para os membros da categoria indicada, em comparação ao grupo de referência (omitido) formado pelo conjunto do topo da estrutura social. Os modelos com controles incorporam as variáveis raça, gênero, setor econômico, região geográfica, dimensão da área urbana, tempo de trabalho e horas trabalhadas. Gênero foi expresso de forma binária. Raça diferencia o grupo branco e o não branco. Foram seis os setores econômicos considerados (indústria de transformação, indústria extrativa, serviços produtivos, serviços de distribuição, serviços sociais e serviços pessoais). As regiões envolvem Sudeste, Sul, Nordeste, Centro-Oeste e Norte; a dimensão da área urbana demarca região metropolitana, municípios auto representativos (proxy para médio porte) e demais municípios. 0 tempo de trabalho foi estimado pela idade atual diminuída da idade quando a pessoa começou a trabalhar; as horas de trabalho na semana são relativas ao trabalho principal, por motivo de ajuste com a renda. 0 tipo de composição familiar, baseada na variável v4723 originária da PNAD, considera a combinação de casal, mãe sem cônjuge, filhos e idade dos filhos, tomando 14 anos como divisor.

0 estudo utiliza os microdados da Pesquisa Nacional por Amostra de Domicílios - PNAD, levantados pelo IBGE. Foram excluídos nos anos recentes os dados da zona rural da região Norte, exclusive Tocantins, com a finalidade de comparação com os anos anteriores a 2004. Tendo em vista que a classificação de classe social foi construída com base em informações sobre o trabalho principal, utiliza-se em todas as análi- ses a renda do trabalho principal, por motivo de ajuste. A renda mediana usada no estudo foi expressa em valores de 2011 usando deflatores baseados no INPC, com ajustes na transição para o Plano Real (CORSEUIL; FOGUEL, 2002).

0 estudo está estimando discrepâncias entre categorias extremas da estrutura social e efeitos de classe bastante fortes. Todas as categorias são formadas por muitos casos. Tudo isso favorece sobremaneira a significância e a precisão das estimativas que, com regressão logística foram ajustadas ao desenho complexo do plano amostral da PNAD, com o comando "svy do Stata". A passagem para uma estimativa com ajuste ao desenho amostral não mostrou impacto relevante na significância estatística dos resultados. Os coeficientes foram estimados com intervalos de confianças de $99 \%$. A inspeção dos coeficientes e intervalos de confiança das categorias de interesse do estudo (base da estrutura social) não desperta nenhuma preocupação razoável.

0 conceito de pobreza relativa de recursos expressa um limiar crítico de assimetria na posse e comando de um estoque de bens acumulados no tempo. Foi mensurado neste estudo como uma linha móvel baseada no valor inferior a 70\% da mediana de um indice ponderado de patrimônio habitacional e bens de consumo duráveis. 0 índice foi composto de dez itens. Quatro itens visam retratar a habitação, que é o tipo de patrimônio mais importante que a maioria das pessoas pode ter além da condição ou não de proprietário, três outros itens foram escolhidos de modo a retratar o padrão inferior, mediano e superior de habitação. Habitação com água encanada em pelo menos um dos cômodos diferencia por contraponto o padrão inferior (96\% têm água encanada), com seis cômodos ou mais o me- 
diano (53\% têm) e com dois banheiros ou mais o superior (29\% têm) em 2011. Nos itens relativos particularmente a bens de consumo duráveis, procurou-se contemplar tanto itens mais difundidos quanto mais diferenciados. Eles incluem posse de televisão colorida, geladeira, freezer (ou geladeira de duas portas), máquina de lavar, computador e telefone fixo. No espírito da noção de pobreza relativa os itens foram ponderados conforme o seu grau de escassez, ou seja, quanto mais escasso maior o seu peso. 0 coeficiente de confiabilidade da escala (alpha de (ronbach) envolvendo estes itens é de 0,7197. 0 índice de recursos varia na amostra estudada de 0,48 a 4,09, com 2,26 de mediana, média de 2,22 e 0,39 de coeficiente de variação.

\section{Chances relativas de classe de ser pobre no Brasil}

0 trabalho avalia as chances relativas das categorias de classe da base da estrutura social de se encontrarem numa situação de pobreza relativa. Num primeiro momento, antes de estimar as chances relativas através de modelos logísticos, cabe considerar a evolução da incidência de pobreza relativa nas categorias de classe. Observa-se então a dimensão do que vai ser confrontado, ou seja, os níveis prevalecentes de pobreza conforme os critérios usados. Isso é importante, pois a análise das chances relativas de ser pobre não considera nem o tamanho das categorias de classe nem a alteração dos níveis de pobreza. Ela avalia essencialmente as chances relativas entre duas categorias de estar num nível de pobreza que pode even- tualmente ter se tornado maior ou menor. Esta característica da noção de chances relativas faz com que ela possa ser usada para comparar momentos e situações que diferem na distribuição dos casos entre as categorias. 0 foco em diferenças observadas tem naturalmente limitação, pois parte do que está sendo observado nas categorias pode se dever a outros fatores, como região, por exemplo, e não propriamente a um efeito de classe social. Nos modelos estatísticos, estes outros fatores vão ser controlados de modo a isolar mais apropriadamente o efeito de classe social.

A Tabela 1 mostra a evolução da pobreza de renda, da pobreza de recursos, da prevalência de um dos dois tipos de pobreza e do acúmulo simultâneo de ambos os tipos de pobreza. A proporção de pobres pode ser vista como uma estatística simples do risco absoluto de pobreza para um grupo (LAYTE; WHELAN, 2002). Estes dados apresentados se baseiam na mediana do trabalho principal dos que têm uma posição de classe que tende a ser mais elevada do que o valor para o conjunto da população. São apresentados também os dados de 2009 para o critério de renda, pois a elevação significativa da renda mediana em 2011 (em que se baseia a medida) alterou bastante a incidência da pobreza relativa no critério de renda do trabalho principal. 0 indicador de pobreza de recursos construído não pode ser operacionalizado para o ano de 1992 de forma comparável com o período mais recente. Não são apresentados dados de pobreza de recursos para 2009 já que o indicador não é afetado por flutuações da mediana e reflete um processo de acúmulo de bens que se dá no curso do tempo. 
Tabela 1 - Incidência de pobreza relativa (\%) em categorias de classe dos indivíduos. Brasil, 1992-2011.

\begin{tabular}{llllllllllll} 
Categorias de classe & \multicolumn{4}{c}{ Pobreza de renda } & \multicolumn{2}{c}{ P. recursos } & \multicolumn{2}{c}{ Um tipo * } & \multicolumn{2}{c}{ Ambos ** } \\
& 1992 & 2002 & 2009 & 2011 & 2002 & 2011 & 2002 & 2011 & 2002 & 2011 \\
Topo privilegiado & 3,3 & 3,9 & 1,8 & 4,3 & 7,8 & 3,4 & 10,1 & 7,0 & 1,6 & 0,7 \\
Autônomo agrícola & 53,7 & 59,9 & 50,5 & 63,9 & 66,4 & 58,7 & 77,3 & 76,1 & 49,1 & 46,5 \\
Trabalhador típico & 14,2 & 22,9 & 9,1 & 22,9 & 38,0 & 22,4 & 48,5 & 36,2 & 12,4 & 9,1 \\
Trabalhador elementar & 48,9 & 58,7 & 31,9 & 52,8 & 72,9 & 55,1 & 83,8 & 72,3 & 47,7 & 35,6 \\
Autônomo precário & 47,0 & 49,4 & 46,4 & 43,8 & 49,6 & 32,3 & 70,0 & 57,0 & 29,0 & 19,0 \\
Empregado doméstico & 62,3 & 69,7 & 49,1 & 67,4 & 57,1 & 37,5 & 81,7 & 72,8 & 45,2 & 32,2 \\
Agrícola precário & 76,9 & 84,9 & 76,9 & 84,9 & 86,7 & 75,6 & 95,4 & 91,8 & 76,3 & 68,7 \\
Total & 28,9 & 33,6 & 21,0 & 30,5 & 41,8 & 26,4 & 53,3 & 41,8 & 22,0 & 15,1
\end{tabular}

Nota: * Presença de um ou outro tipo de pobreza. ** Presença cumulativa dos dois tipos de pobreza. As proporções estimadas são estatisticamente significativas ao nível de 0,01 ou mais. A mediana foi baseada na renda das categorias de classe e não do conjunto da população.

No geral, os indicadores descritivos de pobreza de renda aumentaram em 2002, entraram em queda de lá até 2009, mas aumentaram depois de modo a ultrapassar o patamar de 1992 - esse aumento, no entanto, se deve à elevação da mediana em 2011. As categorias de assalariados tiveram um melhor desempenho no período de 2002 a 2011. 0 trabalhador típico sempre esteve abaixo da incidência percentual geral de pobreza, e as demais categorias não privilegiadas sempre acima. Num movimento diferenciado do critério de renda, a proporção de pobreza de recursos experimentou uma redução ponderável ou expressiva para todas as categorias estampadas. Todas as posições destituídas, do trabalhador elementar ao agrícola precário, encontram-se num tipo de situação de pobreza, na maioria dos casos num patamar superior aos 70\%. A marcante diferença entre a incidência de uma das formas de pobreza e a ocorrência simultânea de ambas as formas mostra que os dois critérios não convergem. Este fenômeno sugere a limitação de focalizar apenas a renda sem olhar para o acesso a recursos e vice-versa. As duas dimensões devem ser levadas em conta tendo em vista as diferenças de natureza, implicação e incidência entre essas situações. Pesquisas sobre pobreza e privação na União Europeia têm constatado uma significativa disjunção (mismatch) entre as medidas baseadas em renda e os indicadores não monetários de privação material. Este nível de disjunção existe tanto na mensuração transversal quanto longitudinal. A renda parece não captar apropriadamente o padrão de vida dos domicílios decorrente da relação entre comando sobre recursos e necessidades (NOLAN; WHELAN, 2011).

A Tabela 2 mostra como evoluíram as chances relativas (odds ratio), já convertidas em percentagem, de se estar numa situação de pobreza relativa. 0 grupo de comparação (omitido) é formado pelo bloco de posições privilegiadas de classe composto por capitalista, especialista autônomo, empregado especialista e gerente. Esse agrupamento perfaz 9\% da estrutura social em 2011. Tendo em vista a mudança do li- 
miar de pobreza relativa, devido à ponderável elevação da mediana em 2011, são apresentadas também as estimativas para 2009. Essa elevação significativa da renda mediana serve para mostrar, numa espécie de experimento natural, como os diferentes grupos acompanham ou se defasam quando ocorre uma melhora no patamar da renda disponivel e como isso afeta a sua posição relativa face ao novo limiar de pobreza que se estabelece. 0 fato da linha de pobreza relativa elevar-se com o aumento do nível geral da renda reflete o processo de "interdependência dos padrões de vida” (ATKINSON, 1976). Note-se, em primeiro lugar, que o condicionamento de classe sobre a chance relativa de pobreza é muito elevado. Regra geral, alguém, em posição destituída, tem uma chance $1400 \%$ a mais, quando não maior, de ser pobre relativamente falando no contraste com alguém em posição privilegiada. 0 trabalhador típico tem uma posição melhor, mas ainda hoje tem uma chance 588\% maior. No conjunto do período, as chances relativas de ser pobre se reduziram até 2009 para as categorias de trabalhador elementar e empregado doméstico, mas voltaram a subir fortemente em 2011, indicando que as oportunidades destes grupos ficaram defasadas no curso do processo de elevação da mediana.
0 contraste realizado com a pessoa de referência da família (PRF), que representa uma forma de tomar a família como unidade de análise, mostra, ao final do período, uma desigualdade de classe mais intensa nas chances relativas de ser pobre. A pessoa de referência da família tende a apresentar uma situação de classe mais favorável do que os demais membros. Isso significa que os mais privilegiados têm pessoas de referência ainda mais proeminentes. Ao serem comparadas as famílias com este indicador, no ano de 2011 as discrepâncias de oportunidades de ser ou não ser pobre entre as classes mostram-se ainda maiores, revertendo um padrão inverso que antes predominava. Note-se, por fim, que as chances de classe de ser pobre da pessoa de referência não são afetadas pelo tipo de composição familiar (FAM), pois as estimativas são pouco alteradas ao ser agregada esta variável. 0 coeficiente da família formada por mãe com filhos menores (não mostrado aqui) mostra que esta tem mais chance de ser pobre de renda, ao controlar por classe, raça, gênero e os demais fatores, mas isso não afeta as chances de classe de ser pobre em relação ao grupo privilegiado. Note que este padrão não pode ser generalizado para outros contrastes de classe diferentes deste grupo de comparação. 
Tabela 2 - Chances relativas (\%) de pobreza de renda em comparação ao topo privilegiado. Brasil, 19922011. Modelos com controles.

Categorias de classe

Autônomo agrícola
Trabalhador típico
Trabalhador elementar
Autônomo precário
Empregado doméstico
Agrícola precário
Pseudo R2 *

\begin{tabular}{llll}
\multicolumn{5}{c}{ Classe do individuo } \\
1992 & 2002 & 2009 & 2011 \\
976 & 1686 & 1774 & 2733 \\
338 & 604 & 288 & 588 \\
1074 & 2409 & 988 & 2206 \\
1579 & 1684 & 2120 & 1428 \\
2078 & 2487 & 1322 & 2123 \\
1653 & 3995 & 3747 & 6176 \\
0,33 & 0,32 & 0,38 & 0,30
\end{tabular}

\begin{tabular}{llll}
\multicolumn{3}{c}{ PR Família } & +FAM \\
1992 & 2002 & 2011 & 2011 \\
763 & 1475 & 2819 & 2796 \\
240 & 511 & 663 & 657 \\
877 & 2577 & 2959 & 2954 \\
1419 & 1581 & 1794 & 1787 \\
1795 & 2126 & 2634 & 2682 \\
1334 & 3386 & 6496 & 6445 \\
0,34 & 0,35 & 0,34 & 0,34
\end{tabular}

Fonte: Tabela A-1 do Anexo Estatístico.

Nota: * Vide nota no anexo. Estimativas realizadas com todas as categorias da tipologia de classes. Coeficientes estatisticamente significativos ao nível de 0,0001. PR Família: pessoa de referência da família. FAM: composição familiar.

Tendo em vista os limites do critério de renda, o trabalho introduz, com a Tabela 3, a noção de pobreza relativa de recursos, visando captar outras dimensões da privação relativa e da insegurança econômica. Os dados da Tabela mostram que as chances relativas de ser pobre de recursos, em comparação ao grupo privilegiado, pouco se alteraram ou se deterioram para os que têm desvantagens de classe. Ao se mudar a unidade de análise do indivíduo para a pessoa de referência da família, a desvantagem de classe aumenta. Esta última opção oferece possivelmente um melhor ajuste, pois o indicador de recursos construído foi aferido ao nível do domicílio. 0 tipo de família da pessoa de referência não explica o padrão existente de chances re- lativas de classe de ser pobre de recursos, no contraste entre base e topo da estrutura social, pois o seu controle não reduz a diferença. Ao contrário, o tipo de família funciona como uma espécie de variável de supressão do efeito original. Isto significa que as discrepâncias seriam um pouco maiores se não fossem as diferenças de tipos de família, já que elas crescem quando este fator é controlado. A família formada por mãe com filhos menores tem mais chance de ser pobre de recursos, ao se controlar por classe, raça, gênero e demais fatores (dados não mostrados na Tabela). Entretanto, o controle da composição familiar aumenta a chance de ser pobre nestas categorias de classe social em relação ao grupo privilegiado. 
Tabela 3 - Chances relativas (\%) de pobreza de recursos em comparação ao topo privilegiado. Brasil, 20022011. Modelos com controles.

\begin{tabular}{llllll}
\hline & \multicolumn{3}{c}{ Indivíduo } & \multicolumn{3}{c}{ PR Família } \\
Categorias de Classe & 2002 & 2011 & 2002 & 2011 & + FAM \\
& 451 & 782 & 518 & 844 & 900 \\
Autônomo agrícola & 482 & 506 & 576 & 565 & 596 \\
Trabalhador típico & 1290 & 1377 & 1596 & 1594 & 1694 \\
Trabalhador elementar & 654 & 684 & 746 & 733 & 761 \\
Autônomo precário & 1049 & 1097 & 1202 & 1125 & 1238 \\
Empregado doméstico & 1116 & 1247 & 1379 & 1377 & 1457 \\
Agrícola precário & 0,21 & 0,24 & 0,23 & 0,24 & 0,26 \\
Pseudo R2 * & & & & & \\
\end{tabular}

Fonte: Tabela A-2 do Anexo Estatístico.

Nota: * Vide nota no anexo. Estimativas realizadas com todas as categorias da tipologia de classes. Coeficientes estatisticamente significativos ao nível de 0,0001. PR FAMíLIA: pessoa de referência da família. FAM: composição familiar.

A comparação entre as chances de pobreza de renda e de pobreza de recursos mostra-se informativa. As desigualdades de chances relativas de ser pobre dos indivíduos são muito mais pronunciadas no critério de renda do que no de recursos. Esse resultado parece refletir tanto a existência de maior dispersão na renda pessoal, quanto a menor capacidade do indicador de recursos de captar discrepâncias, pois este apresenta um coeficiente de variação baixo. No período pós 2002 as discrepâncias de classe entre os indivíduos aumentam para os estratos agrícolas em ambos os critérios. Entretanto, nas demais categorias, as desigualdades caem no critério de renda e aumentam um pouco no critério de acúmulo de bens. Na verdade, as reduções mais ponderáveis ocorrem basicamente no critério de renda para as categorias de autônomo precário e empregado doméstico . 0 quadro configurado na análise da pobreza relativa parece refletir o fato de que as oportunidades comparativas de acumulação de recursos, mensuradas por um indicador que leva em conta a escassez relativa desse estoque de bens, mostra-se menos suscetivel de alterações do que os fluxos de renda.

\section{Considerações finais}

0 estudo conjugou o uso de classe como determinante de resultados e o foco na pobreza relativa como resultado a ser aferido. Uma parte ponderável das posições destituídas de ativos de valor, devido aos processos de exclusão, insuficiência ou depreciação de ativos, não é pobre relativamente falando. Entretanto, a incidência da pobreza, quando computada a presença de alguma das duas formas, renda ou recursos, chega a atingir mais de dois terços das pessoas. A mensuração da pobreza relativa mostrou-se como um instrumento revelador para olhar para a realidade brasileira. Ela capta mudanças importantes na posição relativa dos grupos. 0 tratamento da noção de pobreza de recursos agregou uma dimensão diferenciada que não é captada pela informação sobre renda. Algumas categorias na base da estrutura social são mais pobres de renda e outras no plano dos 
recursos. A divergência na incidência dos dois tipos de desvantagem, embora em parte reflita diferenças na unidade de análise (indivíduo ou família), mostra que ambos os fatores precisam ser considerados na avaliação do padrão de vida. A disjunção constatada entre os dois indicadores revela um aspecto positivo, já que a sua sobreposição seria o pior dos mundos. 0 resultado sinaliza a importância de aprofundar o entendimento da divergência entre os fluxos de renda e o acúmulo de recursos no âmbito dos grupos em desvantagem.

A diminuição da incidência proporcional da pobreza relativa após 2002 pode ser vista como um benefício geral, mas isso não quer dizer que todos tenham se beneficiado igualmente do que ocorreu. As discrepâncias de classe social nas chances relativas de ser pobre mantiveram-se em níveis muito elevados ou ampliaram-se no conjunto do período. No subperíodo pós 2002, as chances relativas de se estar em situação de pobreza relativa de renda, em contraste com o topo privilegiado, excetuando os dois estratos agrícolas, melhoraram um pouco para os demais grupos da base ao se focalizar o individuo como unidade de análise. Ao se tomar a pessoa de referência da família como unidade, as chances relativas pioraram para todos na base, inclusive na década mais recente. A desigualdade no processo de acúmulo de recursos, que considera a distribuição relativa dos bens e das chances de obtê-los, embora mostre discrepâncias menores de chances relativas na comparação com a renda, revela-se persistente no período recente pós 2002.

0 estudo mostrou a pertinência da adoção de uma linha móvel de pobreza relativa para a análise da realidade nacional. Além disso, indicou a necessidade de agregar a consideração da pobreza de recursos na avaliação do padrão de vida. A tese do potencial extensivo e da estruturação social dos riscos de pobreza orientou uma investigação incomum no Brasil das desigualdades de classe nas chances relativas de estar em situação de pobreza, num contexto de queda da desigualdade da renda. Embora a incidência da pobreza relativa tenha se alterado no período, com altos e baixos entre $33,6 \%$ e $21 \%$, isso não mudou o condicionamento de classe dos riscos de pobreza, em termos comparativos, de um modo consistentemente mais favorável aos grupos mais vulneráreis. Num contraponto aos estudos e debates atuais que se fixam unilateralmente nos padrões de incidência da pobreza e em distinções entre os pobres, o estudo demonstrou, para o caso brasileiro, como um resultado geral (positivo ou negativo) pode ser repartido sem alterações consistentes e marcantes nas oportunidades relativas dos grupos em maior desvantagem.

A pobreza envolve processos de exclusão, restrição ou depreciação de recursos que levam a um padrão de vida insuficiente e a uma inserção social desfavorável na sociedade. As circunstâncias que caracterizam a condição de pobre estão se alterando e alimentando mudanças nos limiares de pobreza que se movem no curso do tempo. Os grupos e os indivíduos podem em diferentes graus ultrapassar, acompanhar ou se defasar em relação ao novo padrão de vida que se tornou disponível. Pobreza não é um estado permanente que adere a um grupo relativamente fixo de pessoas com determinados atributos compondo um circuito fechado. Não parece fazer sentido sociológico a ideia de categorias de risco total ou risco zero de pobreza. Num sentido mais geral, pobreza é uma questão de riscos, não estritamente confınados, que são alimentados e precipitados por diferentes tipos de 
dinâmicas e circunstâncias adversas em operação na sociedade (estruturais, contextuais, conjunturais, herdadas, acumuladas) e os seus desdobramentos, transbordamentos e ramificações. Os deslocamentos entre os limiares de pobreza, em processos duráveis ou temporários, envolvem a conjugação de fatores protetivos que minimizam riscos e vulnerabilidades que potencializam riscos. As múltiplas vantagens e os diversos fatores protetivos de determinados grupos podem isolar, embora nunca completamente, os seus membros dos riscos de pobreza, que tendem a virar eventos mais raros. As categorias da base da pirâmide social podem ficar em melhores circunstâncias e verem reduzidas parte das antigas vulnerabilidades. Entretanto, os descompassos entre os níveis de progressos e defasagens, em relação aos novos limiares de padrão de vida que se estabelecem, em conjunção com a distribuição de proteções e vulnerabilidades entre os grupos, podem estabilizar ou mesmo amplificar as desigualdades em oportunidades de se ingressar numa situação de empobrecimento relativo. Os progressos nos padrões de vida da população brasileira no período não se fizeram acompanhar de reduções marcantes - na distribuição relativa de fatores protetivos que minimizam riscos -, e de vulnerabilidades que potencializam riscos de estar em situação de pobreza relativa - no contraste entre o topo e a base da estrutura social. Avanços na redução das desigualdades de classe de recompensas e de oportunidades relativas de estar em situação de pobreza implicam possivelmente em políticas econômicas e sociais que diminuam de modo mais significativo, com ações redistributivas diretas ou indiretas, os níveis elevados de assimetrias de poderes e direitos sobre os recursos geradores de valor.

\section{Referências}

ATKINSON, A.B. The economics of inequality. Oxford: Clarendon Press, 1976.

ATKINSON, A.B. Poverty in Europe. Oxford: Blackwell, 1998.

BOURGUIGNON, F. From income to endowments: the difficult task of expanding the income poverty paradigm. In: GRUSKY, D.; KANBUR, R. (Orgs.). Poverty and inequality. Stanford: Stanford University Press, 2006.

BRADY, D. Rethinking the sociological measurement of poverty. Social Forces. v. 81, n. 3, p. 715752, 2003.

CORSEUIL, C.H.; FOGUEL, M.N. Uma sugestão de deflatores para rendas obtidas a partir de algumas pesquisas domiciliares do IBGE. Texto para Discussão, n. 897, Brasília: IPEA, 2002, p. 1-8, 2002.

FURTAD0, C.S.V. Classificação dos pobres: questões, construção e análise. Sociologias, v. 13, n. 26, p. 306-330, 2011.

GOLDTHORPE, J.; MCKNIGHT, A. The economic basis of social class. In: MORGAN S. et al. (Orgs.). Mobility and inequality. Stanford: Stanford University Press, 2006, p. 109-136.

GOLDTHORPE, J. Analyzing social inequality. European Sociological Review, v. 26, n. 6, p. 731-44, 2010.

GRUSKY, D.; KANBUR, R. (Orgs.). Poverty and inequality. Stanford: Stanford University Press, 2006.

GRUSKY, D.; WEEDEN, K.A. Measuring poverty: the case for a sociological approach. In: KAKWANI, N.; SILBER, J. (Orgs.). Many dimensions of poverty, New York: Palgrave Macmillan, 2008, p. 20-35.

HAVEMAN, R.;WOLFF, E. The concept and measurement of asset poverty: levels, trends and composition for the U.S., 1983-2001. Journal of Economic Inequality, v. 2, n. 2, p. 145-169, 2004.

IETS. Pobreza e indigência. Disponível em: < http:// www.iets.org.br/dado/pobreza-e-indigencia $>$. 2013a. Acesso em: 31 out. 2013. 
IETS. Tabulações da PNAD elaboradas pelo IETS (1992-2011). Disponivel em: <http://www.iets.org. br/dados/>. 2013b. Acesso em: 31 out. 2013.

LAYTE, R.; WHELAN, C. Cumulative disadvantage or individualisation? A comparative analysis of poverty risk and incidence. European Societies, v. 4, n. 2, p. 209-233, 2002.

LISTER, R. Poverty. Cambridge: Polity, 2004.

MORILLAS, J.R. Assets, earnings mobility and the black/white gap. Social Science Research, v. 36, n. 2, p. 808-833, 2007.

NOLAN, B.; WHELAN, C. Loading the dice? A study of cumulative disadvantage. Dublin: Oak Tree Press, 1999.

NOLAN, B.; WHELAN, C. Poverty and deprivation in Europe. Oxford: Oxford University Press, 2011.

NOLAN, B.; MARX, I. Economic inequality, poverty and social exclusion. In: SALVERDA, W.; SMEEDING, T.M.; NOLAN, B. The Oxford handbook of economic inequality. Oxford: Oxford University Press, 2011, p. 315-341.

OLIVER, M.; GRANT, D.M. The persistence of poverty in a changing world. In: BLAU, J.R. (org.). The Blackwell companion to sociology. Oxford: Blackwell, 2000, p. 161-77.

OSÓRIO, R.G. et al. Perfil da pobreza no Brasil e sua evolução no período 2004-2009. Texto para Discussão, n. 1647. Brasília: IPEA, p. 1-50, 2011.

PLATT, L. Poverty. In: PAYNE, G. (Org.). Social divisions. 2. ed. New York: Palgrave Macmillan, 2006. p. 275-304.

ROCHA, S. Pobreza no Brasil: afınal, de que se trata? Rio de Janeiro: Ed. FGV, 2006.

ROEMER, J. Free to lose: an introduction to Marxist economic philosophy. Cambridge: Harvard University Press, 1988.

SANTOS, J. A. F. Uma classificação socioeconômica para o Brasil. São Paulo, Revista Brasileira de Ciências Sociais, v. 20, n. 58, p. 27-45, 2005.
SANTOS, J. A. F. Comprehending the class structure specificity in Brazil. South African Review of Sociology, v. 41, n. 3, p. 24-44, 2010.

SANTOS, J. A. F. Esquema de classe para abordar a desigualdade de saúde no Brasil. In: ROSENBERG, F. (Org.). Classes sociais, território e saúde: questões metodológicas e políticas. Rio de Janeiro: Fiocruz, 2014. p. 39-59. Disponivel em: <http://www.forumitaborai. fiocruz.br/node/974>. Acesso em: 14.10.2016.

SEN, A. Social exclusion: concept, applications, and scrutiny. Social Development Papers, n. 1, Asian Development Bank, 2000.

SHAPIRO, T.; MELVIN, 0. Black wealth/white wealth: a new perspective on racial inequality. New York: Routledge, 1995.

SOARES, S. S. D. Metodologias para estabelecer a linha de pobreza: objetivas, subjetivas, relativas e relacionais. Texto para Discussão, n. 1381. Brasília: IPEA, p. 1-49, 2009.

TILLY, C. Durable inequality. Berkeley: University of California Press, 1998.

TILLY, C. Poverty and the politics of exclusion. In: NARAYAN, D.; PETESCH, P. Moving out of poverty: cross-disciplinary perspectives on mobility. Washington: The World Bank, 2007, p. 45-76.

TOWNSEND, P. Poverty in the United Kingdom. London: Allen Lane and Penguin Books, 1979.

WATSON, D.; WHELAN, C.; MAITRE, B. Class and Poverty: cross-sectional and dynamic analysis of income poverty and lifestyle deprivation. In: ROSE, D.; HARRISON, E. Social class in Europe: an introduction to the European Socio-economic Classification. London: Routledge, 2010, p. 191-215.

WILSON, W.J. Social theory and the concept "underclass". In: GRUSKY, D.; KANBUR, R. (Orgs.). Poverty and inequality. California: Stanford University Press, 2006, p. 103-16.

WRIGHT, E. O. Foundations of a neo-marxist class analysis. In: WRIGHT, E. O. (org.). Approaches to class analysis. Cambridge: Cambridge University Press, 2005, p. 4-28. 


\section{Anexo Estatístico}

Tabela A-1 - Chances Relativas (Odds ratio-OR), com Intervalos de Confiança (IC) de 99\%, de estar em Pobreza Relativa de Renda (indivíduos). Brasil, 1992, 2002 e 2011.

\begin{tabular}{|c|c|c|c|c|c|c|c|c|c|}
\hline \multirow{3}{*}{$\begin{array}{l}\text { Variáveis } \\
\text { Autônomo agrícola }\end{array}$} & \multicolumn{3}{|c|}{ PNAD 1992} & \multicolumn{3}{|c|}{ PNAD 2002} & \multicolumn{3}{|c|}{ PNAD 2011} \\
\hline & \multirow{2}{*}{$\begin{array}{l}\mathrm{OR}^{* *} \\
10,78\end{array}$} & \multicolumn{2}{|c|}{ IC $99 \%$} & \multirow{2}{*}{$\begin{array}{l}\mathrm{OR}^{* *} \\
17,86\end{array}$} & \multicolumn{2}{|c|}{ IC $99 \%$} & \multirow{2}{*}{$\begin{array}{l}\mathrm{OR}^{* *} \\
28,33\end{array}$} & \multicolumn{2}{|c|}{ IC $99 \%$} \\
\hline & & 8,62 & 13,49 & & 13,62 & 23,42 & & 22,63 & 35,48 \\
\hline Trabalhador típico & 4,34 & 3,59 & 5,27 & 7,04 & 6,12 & 8,10 & 6,88 & 5,99 & 7,90 \\
\hline Trabalhador elementar & 11,62 & 9,51 & 14,20 & 25,09 & 21,52 & 29,25 & 23,06 & 19,81 & 26,84 \\
\hline Autônomo precário & 16,62 & 13,57 & 20,36 & 17,84 & 15,23 & 20,90 & 15,27 & 13,11 & 17,80 \\
\hline Empregado doméstico & 21,53 & 17,33 & 26,75 & 25,87 & 21,78 & 30,73 & 22,23 & 18,86 & 26,20 \\
\hline Agrícola precário & 17,53 & 13,59 & 22,62 & 40,95 & 25,47 & 65,82 & 62,76 & 42,06 & 93,64 \\
\hline Homem & 0,59 & 0,56 & 0,63 & 0,54 & 0,51 & 0,57 & 0,49 & 0,47 & 0,52 \\
\hline Branco & 0,70 & 0,66 & 0,73 & 0,67 & 0,64 & 0,71 & 0,72 & 0,69 & 0,76 \\
\hline Anos de trabalho & 0,99 & 0,98 & 0,99 & 0,983 & 0,981 & 0,985 & 0,988 & 0,986 & 0,989 \\
\hline Horas trabalho & 0,96 & 0,96 & 0,96 & 0,961 & 0,959 & 0,962 & 0,958 & 0,955 & 0,960 \\
\hline Norte & 0,55 & 0,50 & 0,60 & 0,47 & 0,42 & 0,51 & 0,54 & 0,50 & 0,59 \\
\hline Centro-Oeste & 0,36 & 0,34 & 0,39 & 0,30 & 0,27 & 0,32 & 0,24 & 0,22 & 0,27 \\
\hline Sudeste & 0,26 & 0,24 & 0,27 & 0,23 & 0,21 & 0,45 & 0,21 & 0,20 & 0,23 \\
\hline Sul & 0,26 & 0,24 & 0,28 & 0,22 & 0,19 & 0,25 & 0,18 & 0,16 & 0,20 \\
\hline Ind. de transformação & 0,62 & 0,57 & 0,68 & 0,56 & 0,51 & 0,61 & 0,55 & 0,50 & 0,59 \\
\hline Serv. de distribuição & 0,56 & 0,51 & 0,61 & 0,68 & 0,62 & 0,74 & 0,71 & 0,66 & 0,77 \\
\hline Serv. produtivos & 0,25 & 0,21 & 0,29 & 0,36 & 0,32 & 0,41 & 0,46 & 0,42 & 0,52 \\
\hline Serviços sociais & 0,32 & 0,29 & 0,35 & 0,40 & 0,36 & 0,45 & 0,45 & 0,41 & 0,50 \\
\hline Ind. extrativa & 1,57 & 1,41 & 1,76 & $1,15^{*}$ & 0,97 & 1,38 & $0,93^{*}$ & 0,81 & 1,07 \\
\hline Região Metropolitana & 0,36 & 0,34 & 0,38 & 0,40 & 0,37 & 0,43 & 0,44 & 0,41 & 0,47 \\
\hline Município porte médio & 0,46 & 0,43 & 0,49 & 0,52 & 0,48 & 0,56 & 0,51 & 0,47 & 0,54 \\
\hline Constante & 3,55 & 2,90 & 4,61 & 4,39 & 3,62 & 5,33 & 4,23 & 3,50 & 5,11 \\
\hline Pseudo R2 ${ }^{* * *}$ & 0,33 & - & - & 0,32 & - & - & 0,30 & - & - \\
\hline
\end{tabular}

Fonte: IBGE. PNAD 1992, 2002 e 2011 - Microdados.

Nota: Coeficientes das categorias de classe focalizadas no estudo são estatisticamente significativos ao nível de 0,0001. * Coeficiente estatisticamente não significativo (IC cruza 1 = inexiste associação). ${ }^{* *}$ OR: valor 1 equivale à inexistência de associação estatística. Valores menores que 1 implicam em associação negativa e maiores que 1 em associação positiva. *** Estatística extraída de modelos similares, porém sem ajuste ao desenho amostral complexo da PNAD. Categorias de referência omitidas: classe (bloco privilegiado), cor (não branco), gênero (mulher), região (Nordeste), setor (serviços pessoais) e dimensão urbana (municípios menores). Modelos logísticos com ajuste ao desenho amostral complexo da PNAD. Nos dados de 1992 não foi possivel usar o comando "svy do Stata". Estimativas completas para a pessoa de referência da família e o ano de 2009 podem ser requisitadas ao autor: josealcidesf@yahoo.com.br 
Tabela A-2. Chances Relativas (Odds ratio-OR), com Intervalos de Confiança (IC) de 99\%, de estar em Pobreza Relativa de Recursos (indivíduos). Brasil, 2002 e 2011.

\begin{tabular}{|c|c|c|c|c|c|c|}
\hline \multirow[t]{2}{*}{ Variáveis } & \multicolumn{3}{|c|}{ PNAD 2002} & \multicolumn{3}{|c|}{ PNAD 2011} \\
\hline & $\mathrm{OR}^{* *}$ & IC 9 & $\%$ & $\mathrm{OR}^{* *}$ & IC 9 & $\%$ \\
\hline Autônomo agrícola & 5,51 & 4,53 & 6,70 & 8,83 & 7,19 & 10,83 \\
\hline Trabalhador típico & 5,83 & 5,19 & 6,54 & 6,06 & 5,25 & 7,09 \\
\hline Trabalhador elementar & 13.90 & 12,19 & 15,86 & 14,77 & 12,64 & 17,25 \\
\hline Autônomo precário & 7,54 & 6,66 & 8,54 & 7,84 & 6,71 & 9,15 \\
\hline Empregado doméstico & 11,49 & 9,97 & 13,25 & 11,97 & 10,06 & 14,25 \\
\hline Agrícola precário & 12,16 & 9,54 & 15,49 & 13,47 & 10,60 & 17,10 \\
\hline Homem & 1,36 & 1,31 & 1,42 & 1,31 & 1,26 & 1,37 \\
\hline Branco & 0,58 & 0,55 & 0,61 & 0,60 & 0,57 & 0,63 \\
\hline Anos de trabalho & 0,994 & 0,992 & 0,995 & 0,994 & 0,995 & 0,998 \\
\hline Horas trabalho & $1,000^{*}$ & 0,999 & 1,002 & 0,996 & 0,994 & 0,998 \\
\hline Norte & 0,57 & 0,50 & 0,65 & 0,58 & 0,52 & 0,64 \\
\hline Centro-Oeste & 0,43 & 0,38 & 0,48 & 0,33 & 0,29 & 0,36 \\
\hline Sudeste & 0,37 & 0,34 & 0,41 & 0,24 & 0,22 & 0,26 \\
\hline Sul & 0,22 & 0,20 & 0,25 & 0,19 & 0,17 & 0,21 \\
\hline Ind. de transformação & $0,97^{*}$ & 0,90 & 1,05 & $1,08^{*}$ & 0,99 & 1,18 \\
\hline Serv. de distribuição & 0,77 & 0,71 & 0,83 & 0,78 & 0,72 & 0,85 \\
\hline Serv. produtivos & 0,53 & 0,48 & 0,59 & 0,51 & 0,46 & 0,57 \\
\hline Serviços sociais & 0,56 & 0,51 & 0,61 & 0,61 & 0,55 & 0,67 \\
\hline Ind. extrativa & 1,86 & 1,64 & 2,10 & 1,67 & 1,45 & 1,92 \\
\hline Região Metropolitana & 0,52 & 0,48 & 0,56 & 0,33 & 0,30 & 0,36 \\
\hline Município porte médio & 0,57 & 0,52 & 0,62 & 0,44 & 0,41 & 0,48 \\
\hline Constante & 0,53 & 0,45 & 0,63 & 0,38 & 0,31 & 0,45 \\
\hline Pseudo R2 ${ }^{* * *}$ & 0,21 & - & - & 0,24 & - & - \\
\hline
\end{tabular}

Fonte: IBGE. PNAD 2002 e 2011 - Microdados.

Nota: Coeficientes das categorias de classe focalizadas no estudo são estatisticamente significativos ao nível de 0,0001. * Coeficiente estatisticamente não significativo (IC cruza 1 = inexiste associação). ${ }^{* *}$ OR: valor 1 equivale à inexistência de associação estatística. Valores menores que 1 implicam em associação negativa e maiores que 1 em associação positiva. ${ }^{* * *}$ Estatística extraída de modelos similares, porém sem ajuste ao desenho amostral complexo da PNAD. Categorias de referência omitidas: classe (bloco privilegiado), cor (não branco), gênero (mulher), região (Nordeste), setor (serviços pessoais) e dimensão urbana (municípios menores). Modelos logísticos com ajuste ao desenho amostral complexo da PNAD. Estimativas completas para a pessoa de referência da família e o ano de 2009 podem ser requisitadas ao autor: josealcidesf@yahoo.com.br 
RESUMO

0 artigo analisa a evolução, no período de duas décadas, da associação entre classe social e chances de ser pobre nos critérios de renda e de recursos no Brasil. Modelos de regressão logística foram usados para estimar as chances relativas (odds ratio), ajustadas, de estar em situação de pobreza relativa (limiar de 70\% da mediana). Na base da estrutura social, as desigualdades de oportunidades relativas de ser pobre no critério de renda pessoal disponível, em comparação ao topo privilegiado, mantiveramse em níveis muito elevados ou ampliaramse. As chances relativas de ser pobre de recursos ou bens acumulados no período pós 2002 se alteraram pouco ou tiveram certa deterioração para os que têm desvantagens de classe. Os progressos nos padrões de vida da população não se fizeram acompanhar de reduções marcantes na distribuição relativa de fatores protetivos que minimizam riscos e de vulnerabilidades que potencializam riscos de estar em situação de pobreza relativa no contraste entre o topo e a base da estrutura social.

\section{PALAVRAS-CHAVE}

Pobreza relativa. Classe social. Estrutura social. Renda e recursos. Sociedade brasileira.

\section{ABSTRACT}

The article analyzes over two decades the evolution of the association between social class and chances of being poor in the criteria of income and assets in Brazil. Logistic regression models were used to estimate the adjusted odds ratio of being in relative poverty $(70 \%$ of the median threshold). At the bottom of the social structure, compared to the privileged top, relative inequalities of opportunities of being poor in the criterion of personal income remained at very high levels or increased. The relative odds of being poor in assets in the period after 2002 have changed little or have some deterioration for those at disadvantages. Progress in living standards of the population was not accompanied by a marked reduction in the unequal distribution of protective factors that minimize risks and vulnerabilities that enhance risk of being in relative poverty in the contrast between the top and the bottom of the social structure.

\section{KEYWORDS}

Relative poverty. Social class. social structure. Income and resources. Brazilian society. 